\title{
Bradykinin: Inflammatory Product of the Coagulation System
}

\author{
Zonne Hofman $^{1,2}$ • Steven de Maat ${ }^{1}$ - C. Erik Hack ${ }^{2}$. Coen Maas ${ }^{1}$ \\ Published online: 28 April 2016 \\ (C) The Author(s) 2016. This article is published with open access at Springerlink.com
}

\begin{abstract}
Episodic and recurrent local cutaneous or mucosal swelling are key features of angioedema. The vasoactive agents histamine and bradykinin are highly implicated as mediators of these swelling attacks. It is challenging to assess the contribution of bradykinin to the clinical expression of angioedema, as accurate biomarkers for the generation of this vasoactive peptide are still lacking. In this review, we will describe the mechanisms that are responsible for bradykinin production in hereditary angioedema (HAE) and the central role that the coagulation factor XII (FXII) plays in it. Evidently, several plasma parameters of coagulation change during attacks of HAE and may prove valuable biomarkers for disease activity. We propose that these changes are secondary to vascular leakage, rather than a direct consequence of FXII activation. Furthermore, biomarkers for fibrinolytic system activation (i.e. plasminogen activation) also change during attacks of HAE. These changes may reflect triggering of the bradykinin-forming mechanisms by plasmin. Finally, multiple lines of evidence suggest that neutrophil activation and mastcell activation are functionally linked to bradykinin production. We put forward the paradigm that FXII functions as a 'sensor molecule' to detect conditions that require bradykinin release via crosstalk with cell-derived enzymes. Understanding the mechanisms that drive bradykinin generation may help to identify angioedema patients that have
\end{abstract}

Coen Maas

c.maas-4@umcutrecht.nl

1 Laboratory of Clinical Chemistry and Hematology, University Medical Center Utrecht, Utrecht, The Netherlands

2 Laboratory of Translational Immunology, University Medical Center Utrecht, Utrecht, The Netherlands bradykinin-mediated disease and could benefit from a targeted treatment.

Keywords Angioedema $\cdot \mathrm{HAE} \cdot$ Histamine $\cdot$ Bradykinin $\cdot$ Factor XII · Plasmin · D-dimer

$\begin{array}{ll}\text { Abbreviations } \\ \text { ACE } & \text { Angiotensin-converting enzyme } \\ \text { C1-INH } & \text { C1-inhibitor } \\ \text { FVII } & \text { Factor VII } \\ \text { FXI } & \text { Factor XI } \\ \text { FXII } & \text { Factor XII } \\ \text { HAE } & \text { Hereditary angioedema } \\ \text { HK } & \text { High molecular weight kininogen } \\ \text { NET } & \text { Neutrophil extracellular trap } \\ \text { PAI } & \text { Plasminogen activator inhibitor } \\ \text { PPK } & \text { Plasma prekallikrein } \\ \text { PK } & \text { Plasma kallikrein } \\ \text { r-tPA } & \text { Recombinant tissue plasminogen activator } \\ \text { tPA } & \text { Tissue plasminogen activator } \\ \text { uPA } & \text { Urokinase plasminogen activator } \\ \text { TF } & \text { Tissue factor }\end{array}$

\section{Introduction}

Angioedema is characterized by local, non-itchy, cutaneous or mucosal edema that lasts for hours up to a few days. Angioedema is by definition a pathophysiologic process involving increased permeability of the vascular endothelial lining of small blood vessels (mostly post-capillary venules). The clinical picture of angioedema is well-defined, but the underlying mechanisms responsible for the swellings are not fully understood. Two vasoactive agents are implicated in mediating swelling 
attacks in angioedema. The first is histamine, released by mast cells or basophils. Histamine is the main suspect mediator in allergic reactions, since angioedema can be seen in anaphylaxis [1] or as a concurrent symptom of the mast-cell-driven diseases like chronic spontaneous urticaria [2]. For angioedema with unknown aetiology (idiopathic angioedema), histamine receptor antagonists are clinically applied on a trial-and-error basis, sometimes with higher than recommended doses $[2,3]$. Approximately one in six patients with idiopathic angioedema remains unresponsive to antihistamines [4, 5]. In such cases, the involvement of other mediators should be considered.

The second suspect mediator of angioedema is bradykinin. This vasoactive peptide was first identified as a mediator for angioedema in patients with hereditary angioedema (HAE) [6-8]. Bradykinin is the end-product of the contact activation system. This enzymatic cascade circulates in the plasma and consists of factor XII (FXII), plasma prekallikrein (PPK) and high molecular weight kininogen (HK). This system is linked to the intrinsic coagulation system via factor XI (FXI). Classically, the contact activation system is considered to be a redundant part of the blood coagulation system. In vitro, FXII auto-activates when it binds to negatively charged surfaces such as glass or kaolin, hence the name 'contact system'. Active FXII (FXIIa) activates PPK (Fig. 1). When activated, plasma kallikrein (PK) liberates bradykinin from HK by cleavage. At present time, it is unknown how bradykinin is produced in the human body. Several studies suggested potential natural activators of FXII [9-13], but thus far none of these have been definitively established to induce activation of the contact system during angioedema in vivo.

Here, we will discuss the role of bradykinin in angioedema, the link to the coagulation system and how bradykinin may be produced in vivo.

\section{Bradykinin-Mediated Angioedema}

The available genetic evidence of HAE-related mutations clearly points towards a central role of the plasma contact system in this disease. Most HAE patients have SERPING1 gene mutations (encoding for $\mathrm{C} 1$-inhibitor $(\mathrm{Cl}$-INH) production) $[14,15]$ while a small minority have mutations in the F12 gene, with normal C1-INH activity [16-20].

Hereditary angioedema is hallmarked by recurrent attacks of angioedema. Attacks can be life-threatening when swelling compromises the airways, and extremely painful when located in the intestine $[21,22]$. Therapy targeting the contact system has been successful in HAE, strongly supporting the concept that angioedema is mediated via bradykinin production [23-25]. Evidence for bradykinin involvement in angioedema is not limited to HAE. First, a comparable phenotype can be observed in patients that have acquired $\mathrm{C} 1-\mathrm{INH}$ deficiency due to underlying auto-immune or lymphoproliferative disease [26,
27]. Second, anti-hypertensive drugs that inhibit bradykinin breakdown, such as angiotensin-converting enzyme (ACE), dipeptidyl peptidase IV (DPPIV) or neprilysin (NEP), can induce angioedema. During clinical trials of NEP inhibitors [28], up to $2.17 \%$ of patients and $0.2-0.65 \%$ of patients prescribed ACE inhibitors developed angioedema [29, 30].

Evidently, contact activation is closely linked to the coagulation system [31-33]. Activation of coagulation and fibrinolysis during HAE attacks has been repeatedly reported [34-47]. Yet, HAE patients present with swellings but not with thrombotic tendency [37]. Combined genetic and clinical findings suggest that a subset of coagulation factors are actively involved in angioedema attacks.

\section{Blood Coagulation}

Coagulation factors are readily available throughout the blood circulation to initiate fibrin formation and reinforce platelet plugs at sites of injury. These interactions are essential to ensure a properly functioning hemostatic system (Fig. 1). This system consists of a set of precursor proteins (zymogens) that circulate in the blood and has to be activated to become biologically active. The key initiator of the coagulation system, tissue factor (TF), is normally not present in the circulation. Cells that surround the vessel wall express TF so that only when the endothelial layer is compromised will locally active coagulation take place $[48,49]$. After binding to TF, activated factor VII (FVII) of the extrinsic pathway activates factor $X(\mathrm{FX})$, and to a lesser extent factor IX (FIX) [50]. Activated FX next triggers the formation of a small amount of active factor II (thrombin). Thrombin accelerates coagulation via positive feedback mechanisms. Factor VIII (FVIII), activated by thrombin, forms a complex together with FIX that strongly increases additional FXa and thrombin generation. Thrombin activates factor $V$ (FV) that, in a similar manner, contributes to thrombin formation in complex with FXa. Furthermore, FXI of the intrinsic pathway is also activated by thrombin [51], and additional FIX is being amplified by thrombin activation. Ultimately, thrombin converts fibrinogen into fibrin. Fibrin strands are reinforced through cross-linking by activated factor XIII (FXIII) (also activated by thrombin). The fibrin lattice, together with platelet aggregates and trapped red blood cells, forms a thrombus to seal the damaged area and prevent further haemorrhage. The initiator of this cascade of events, TF, is of vital importance since TF deficiency is lethal and incompatible with normal embryonic development or may cause early death in the perinatal period [52].

\section{Factor XII as a Coagulation Factor}

When blood comes into contact with negatively charged surfaces, FXII activates spontaneously. FXIIa subsequently 


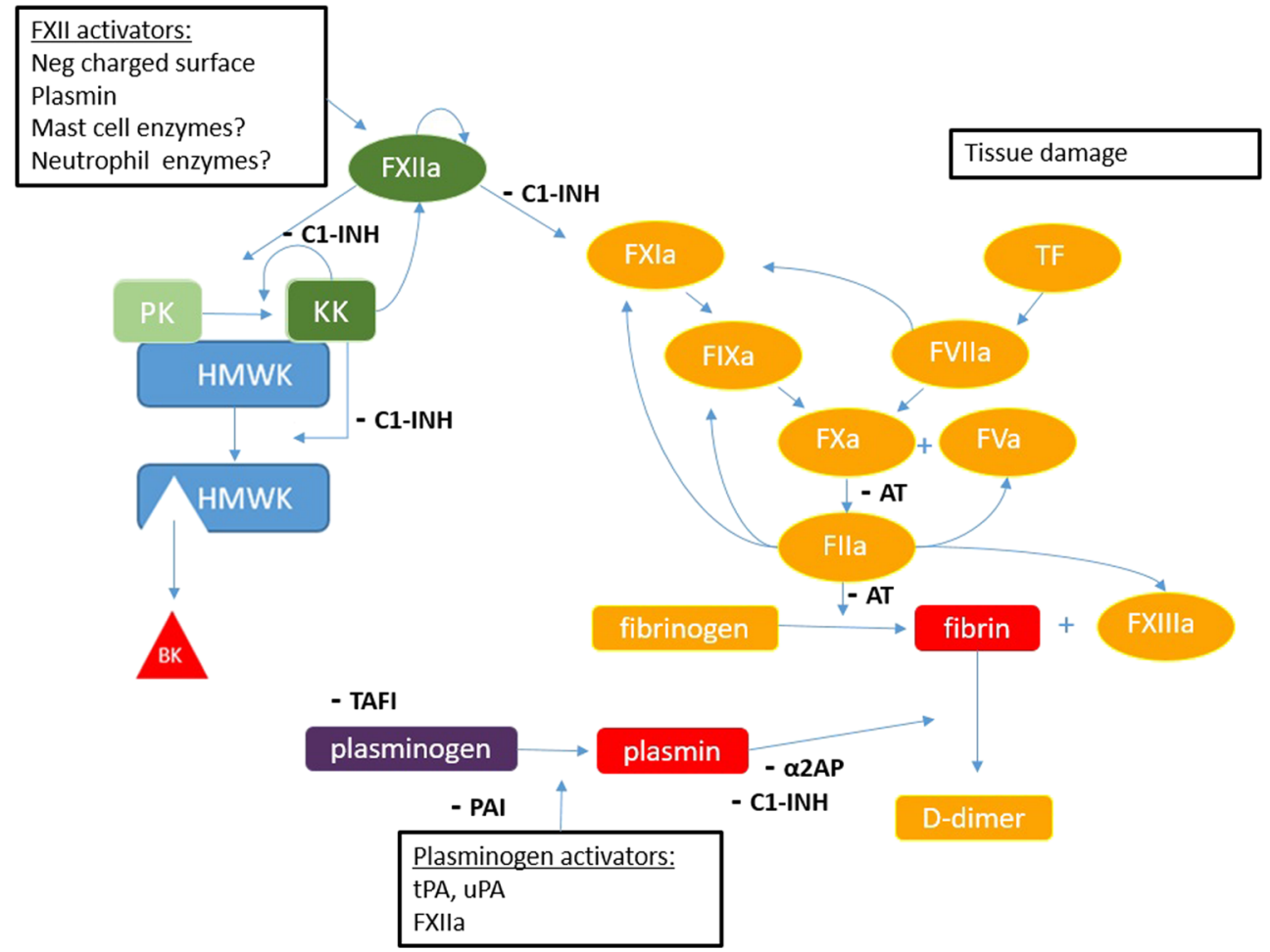

Fig. 1 Overview of coagulation, contact activation and fibrinolysis. The coagulation cascade is initiated by either tissue factor (TF) or FXIIa. Positive feedback by thrombin (FIIa) accelerates coagulation. The endproduct of coagulation is fibrin, cross-linked by factor XIII. Fibrin is degraded by plasmin. During this process, D-dimer, an important clinical biomarker for thrombosis, is generated. Fibrinolysis is started when tPA bound to fibrin, or uPA expressed on the endothelium, converts plasminogen into plasmin. Contact activation starts with the activation of FXII that will eventually lead to bradykinin release and vascular leakage. C1-INH is the most important inhibitor of contact activation and a weak inhibitor of plasmin. Anti-thrombin (AT) inhibits coagulation and

$\alpha 2$-antiplasmin inhibits plasmin; complexes between enzymes and these inhibitors can be measured in plasma as biomarkers for contact activation, coagulation and fibrinolysis. PAI-1 inhibits plasminogen activation via inhibition of tPA and UPA. TAFI modulates plasminogen to prevent activation. Abbreviations: TF tissue factor, FXIIa activate factor XII, PK plasma prekallikrein, KK kallikrein, HMWK high molecular weight kininogen, BK bradykinin, C1-INH C1 inhibitor, AT anti-thrombin, $\alpha 2 A P$ Q2-anti-plasmin, TAFI thrombin activatable fibrinolysis inhibitor, PAI plasminogen activator inhibitor, tPA tissue plasminogen activator, uPA urokinase plasminogen activator activates FXI, thereby providing an alternative trigger for coagulation that is independent of TF-the intrinsic pathway. FXII does not take part in the positive feedback mechanism of thrombin. As a result of the discovery of this in vitro mechanism, FXII is generally regarded as a coagulation factor.

Mysteriously, FXII deficiency is a seemingly asymptomatic condition in both mice and human (Hageman's disease), as it is not associated with a bleeding tendency, unlike deficiencies of other coagulation factors [53]. The same holds for the other components of the contact system cascade; their deficiency does not result in bleeding [54]. This makes the relevance of FXII and the contact system for physiological hemostasis debatable. This logic raises a pertinent question: should FXII be regarded as a coagulation factor, as far as angioedema is concerned? It has been demonstrated that the bradykininproducing contact system machinery can be fully activated in plasma without evidence of coagulation [10, 11, 55]. This might be explained by the physical properties of FXII(a): in a sequence of cleavage events, FXIIa is progressively fragmented. The fragment that remains after multiple cleavages ( $\beta$ FXIIa or FXIIf) has lost its potential for coagulation while its bradykinin-forming potential remains intact.

\section{Factor XII as a Bradykinin-Generating Factor}

Although the relevance of FXII for coagulation and hemostasis seems to be limited to in vitro experiments, this is certainly not the case for bradykinin production. Low levels of bradykinin are continuously formed and present in the bloodstream. Murine models of FXII deficiency indicate that the basal production of bradykinin in plasma is approximately $50 \%$ dependent on FXII [56]. This suggests the presence of a second pathway generating bradykinin in vivo. Several alternative, FXII-independent routes for initiation of bradykinin generation have been identified. The endothelial cell-derived factors heat shock protein 90 (HSP90) and prolylcarboxypeptidase may facilitate FXII-independent 
PPK activation on the endothelial cell surface [57]. Moreover, bradykinin can be directly released from HK by other enzymes than PK; this was recently demonstrated for Mannose Binding Serine Protease 1 [58]. The relevance of these FXIIindependent pathways of bradykinin generation needs to be established. It is imaginable that during endothelial cell activation or damage, small amounts of PPK are activated by these mechanisms, which boost up FXII activation as a result.

The clinical importance of FXII for bradykinin generation was already demonstrated in HAE patients. Genome-wide screening of a subset of HAE patients with normal C1-INH level and function (formerly called type III HAE) resulted in the discovery of disease-related mutations in the F12 gene (named FXII-HAE). Since then, several mutations in HAE patients have been described, (mostly) located in the prolinerich region of FXII (according to mature amino acid sequence: Thr309Arg, Thr309Lys, Ala324Pro, 72-bp deletion at c971_1018p24 and an 18-bp duplication c894_911, and c1681-1G/A in intron 13) [16-20,59]. Additionally, isolated cases of normal C1-INH with FXII mutation have been successfully treated with the bradykinin-receptor antagonisticatibant.

\section{Plasminogen Activation and Fibrinolysis}

After a thrombus has fulfilled its hemostatic function, it has to be cleared. This natural process is mediated mainly by the breakdown of fibrin: fibrinolysis (Fig. 1). Plasmin, the central enzyme of the fibrinolytic system, cleaves the fibrin lattice into smaller fibrin degradation products (FDPs) including D-dimers, which are regarded as a valuable biomarker for thrombosis [60]. Plasmin is generated from its zymogenic precursor plasminogen by either tissue plasminogen activator (tPA) or urokinase plasminogen activator (uPA) [61]. Fibrin provides a platform for its own degradation by binding and potentiating both $\mathrm{TPA}$ and plasminogen. The fibrinolytic system is amenable to inhibition at several stages: plasmin is directly inhibited by $\alpha 2$-antiplasmin, while specific inhibitors of plasminogen activators (PAI-1 and PAI-2) control tPA and UPA [61, 62]. Activation of plasminogen on the fibrin lattice is indirectly prevented by thrombin-activatable fibrinolysis inhibitor, via removal of $\mathrm{C}$-terminal lysines that are needed for the binding of tPA and plasminogen to fibrin. Intriguingly, plasminogen activation on the endothelium can take place in the absence of fibrin when the uPA receptor is expressed [63]. This, amongst others, occurs during tissue injury and hypoxia and makes it attractive to speculate that plasmin may have additional functions beyond fibrinolysis.

\section{A Functional Link Between Plasminogen Activation and Contact System Activation}

As formerly discussed, the most important function of FXII appears to be activation of PPK. Besides that, FXII is also capable of activation of plasminogen $[33,64,65]$. Compared to tPA and uPA, FXIIa is a relatively weak plasminogen activator. However, population studies have proposed that FXIIa may protect against cardiovascular disease via plasminogen activation [66, 67]. This may be attributable to additional interactions between the contact system and the fibrinolytic system: FXIIa can enzymatically inactivate PAI-1 [68], whereas PK stimulates uPA activation on the endothelium [65].

\section{Evidence for Plasmin as Natural FXII Activator}

There is also evidence that the fibrinolytic system triggers the activation of the contact system. It has been demonstrated that plasmin can induce FXII activation in vitro [69]. In line with this finding, patients with myocardial infarction treated with therapeutic plasminogen-activating agents, such as streptokinase or recombinant tPA (r-tPA), showed increased plasma levels of cleaved HK (a surrogate marker for bradykinin release) [69] and elevated plasma levels of FXIIa [70]. Other clinical observations also support the importance of plasmin as a natural FXII activator. Neurologists repeatedly reported angioedema, which is presumably mediated via bradykinin, as a side effect of plasminogen activators given to patients with ischaemic stroke [71-82]. Up to $8 \%$ of stroke patients receiving r-tPA develop angioedema, often located in the oral cavity and lingual region and contralateral to the infarction site [83]. Similar observations were made with other thrombolytic agents [84-86]. A study with 42 post-r-tPA angioedema cases reported that five patients required emergency intubation or cricothyroidotomy due to laryngeal swelling, with fatal outcome in two cases. Notably, concurrent use of ACE inhibitors is also reported in patients who developed angioedema during r-tPA treatment [78, 79, 83]. Evidence for plasmin-dependent bradykinin generation as a cause of angioedema during treatment with fibrinolytic agents is accumulating. However, the majority of these adverse reactions are still treated as a histamine-driven hypersensitivity reaction [86]. Future studies should determine if targeting the contact system is beneficial for treatment of angioedema as a side effect of fibrinolytic therapy. Putting these data together makes a strong case for plasmin-dependent activation of FXII in vivo.

\section{The Involvement of Plasmin in HAE Attacks}

We recently investigated three subtypes of FXII-HAE patients with F12 gene mutations [87] (Unexpectedly, these patients' plasma did not enhance FXII-dependent coagulation after contact with a negatively charged compound in vitro (i.e. 
kaolin). This is in good correspondence with the normal clotting times that were reported in FXII-HAE patients [18]. These patients' plasma also did not become unusually active upon cleavage by plasma kallikrein. Detailed biochemical studies showed that these mutations introduce new cleavage sites in the FXII molecule. The mutated sites are collectively sensitive to cleavage by plasmin, resulting in enhanced susceptibility for activation. Analyses of plasma from two FXIIHAE patients who carry the F12 mutation T309K showed that the plasmin-forming potential correlated with disease activity. These findings underscore the clinical relevance of plasmin as a FXII activator.

Empiric body of evidence for the importance of plasmin in the pathology of HAE has been presented in the last four decades. Anti-fibrinolytic therapy, mainly tranexamic acid, has been used as prophylactic therapy for HAE attacks since the 1970 s $[4,88,89]$. Tranexamic acid is a lysine derivate (analogue) that binds to lysine-binding sites of plasminogen and thereby prevents its binding to fibrin and subsequent activation by tPA or uPA [90]. Moreover, HAE patients with normal $C 1$-INH levels (i.e. FXII-HAE) have decreased levels of PAI-2 during remission compared to patients with HAE due to $C 1-I N H$ deficiency [36]. This suggests that their angioedema episodes might have originated from inadequate inhibition of plasminogen activation and bradykinin formation downstream activated FXII. These findings together point out that plasmin formation and contact system initiation might be linked.

\section{Biomarkers of Contact Activation, Fibrinolytic Activity and Coagulation in Angioedema}

\section{Detection of Contact System Activation}

As bradykinin was already proven to be the pivotal mediator of angioedema, biomarkers for its production or predecessors are highly sought after, as they may help in diagnosis, monitoring disease activity and response to treatment. Bradykinin is only present in the circulation for a few seconds after it is released from $\mathrm{HK}$, due to rapid degradation by kininases [91] which complicates its detection. Activation products of contact system activation in plasma are valuable biomarkers as they may reflect recent bradykinin production. However, due to pre-analytical in vitro activation, accurate measurements have proved to be challenging and relatively labourintensive (see Farkas et al., Chapter 7 in this issue).

Circulating cleaved $H K$ seems to be among the most suitable biomarkers for contact activation since cleaved HK levels have been shown to correlate with attack frequency [92]. Currently, cleaved $H K$ can be detected by immunoblotting [92]. This assay often shows profound cleavage of $\mathrm{HK}$ in citrated plasma from patients with Cl-INH deficiency. A diagnostic tool that could specifically measure cleaved $H K$, only after it has released bradykinin, would be a compelling instrument for HAE diagnosis and follow-up, but is currently lacking.

\section{Biomarkers of Coagulation and Plasminogen Activation}

There is a large base of evidence that contact activation during angioedema attacks is accompanied by changes in the fibrinolytic and coagulation systems that could serve as disease biomarkers [34-47, 93-95]. The understanding that the contact system and fibrinolytic system are functionally linked sheds a new light on the repeatedly reported occurrence of increased levels of complexes of plasmin and its main inhibitor $\alpha 2$ antiplasmin (PAP) and decreased levels of PAI-1 measured during HAE attacks [34-36, 39, 40, 43, 44]. Fibrinolytic biomarkers may also be helpful in identifying bradykinin-mediated angioedema. The presence of these biomarkers in any patient that presents with angioedema in the absence of apparent evidence for thromboembolic event should raise the suspicion that the contact system is involved. Interestingly, parameters of coagulation are repeatedly reported to be increased in HAE. Ddimer levels are elevated during remission periods and markedly increase during attacks [34, 37, 39, 40, 93]. Also, thrombin-anti-thrombin complexes and prothrombin fragments $\mathrm{Fl}+$ $F 2$ increase during attacks [34, 39, 40, 42, 43, 93].

\section{The Paradox of Fibrinolysis in HAE}

Strikingly, HAE is not associated with increased risk of thrombotic disease. It is therefore hard to imagine that the coagulation parameters measured reflect intravascular fibrin formation. Since HAE is associated with extreme vascular leakage, this may offer an alternative explanation for this phenomenon. We would like to propose that when plasma coagulation factors move into the extravascular space, FVIIa may complex with TF. This can trigger coagulation in the absence of vascular injury or intravascular thrombi. Evidence for extrinsic pathway coagulation was demonstrated by a significant increase of FVIIa during angioedema attacks in 14 patients, by Cugno et al. [42]. It would be attractive to hypothesize that increased coagulation parameters in HAE are secondary to massive vascular leakage (Fig. 2). Even though biomarkers for coagulation, such as D-dimer, will not directly reflect bradykinin production, their strong association with HAE may make them helpful as biomarkers for monitoring disease activity.

\section{Future Perspectives in Angioedema-Natural Contact System Activation and Bradykinin Production}

Efforts to identify the initial spark of contact activation focused on the presence of in vivo negatively charged 


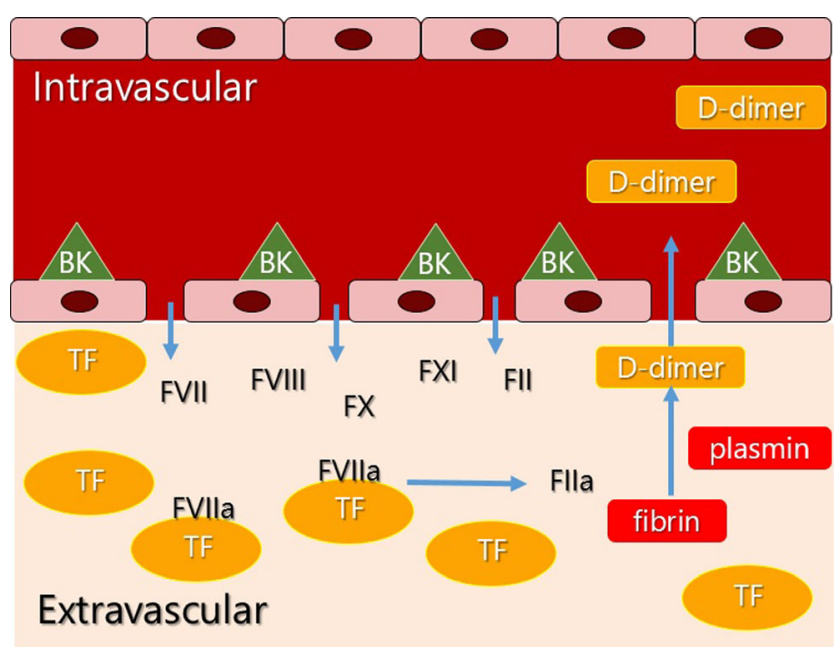

Fig. 2 Proposed model: increased plasma coagulation parameters secondary to increased vascular permeability and extravascular coagulation. Bradykinin binds to its receptors on endothelial cells. Increased vascular permeability allows extravasation of coagulation factors. Tissue factor expressed in the extravascular space can initiate coagulation. In the absence of any injury, the forming fibrin lattice is continuously degraded by plasmin. Subsequently, D-dimer formed in the extra vascular space dissipates into the blood stream. Abbreviations: TF tissue factor, FII factor II, BK bradykinin

compounds (i.e. glycosaminoglycans, misfolded protein aggregates, etc.). The discovery that plasmin can enzymatically activate FXII, in the absence of a surface, provides an alternative mechanism for this activation process. The importance is underscored by observations in HAE and patients receiving $\mathrm{r}$ tPA therapy. Under physiological circumstances, this mechanism may take place at sites of vascular obstruction, or slow perfusion, where the tissues are endangered by hypoxia. Alternatively, minor tissue trauma or infection may provide signals to the vascular endothelium, resulting in local sequestration and activation of the contact system. We postulate that FXII functions as a 'sensor molecule' that interacts with the environment to detect conditions where increased vasopermeability is required. Excitingly, it is possible that a variety of enzymes other than plasmin can fulfil a similar role and contribute to FXII activation.

\section{Neutrophil Activation and Contact System Activation are Functionally Linked}

Recent work shows that HAE attacks are associated with increasing neutrophil counts and neutrophil elastase levels [96]. Neutrophils are important cells for the innate immunity. They migrate out of the bloodstream within hours after a pathogen is detected. Migration of neutrophils to sites of inflammation is orchestrated by several mechanisms, such as chemotaxis by interleukins and complement factors and interaction of neutrophils with endothelial cell receptors [97]. It can be envisioned that neutrophils interact with the contact system to boost neutrophil extravasation by bradykinin-mediated vasodilatation. First of all, neutrophil elastase, released by active neutrophils, inactivates $C 1-I N H$ thereby allowing contact activation to take place [98]. Second, in vitro studies show that the bradykinin B1 receptor (BKB1R) regulates neutrophil trafficking [99, 100]. Third, both kallikrein and FXIIa can induce neutrophil degranulation [101]. Finally, neutrophil extracellular traps (NETs) have been shown to activate FXII. NETs exist of DNA, and the negative charge of DNA is believed to induce autoactivation of FXII [102]. At the very least, NETs can sequester FXII and present it for activating cleavage. NETs are a binding site for antimicrobial proteins such as histones, neutrophil elastase and cathepsins [99]. To what extent the proteins loaded on NETs contribute to neutrophil-induced FXII activation is not yet elucidated. The negative charge of NETs, in combination with potential FXII-activating enzymes, would make neutrophils a plausible platform for contact activation. Further research to neutrophil and FXII activation may help understand its possible relevance for HAE patients.

\section{Mast Cell Activation Is Linked to Bradykinin Generation}

Angioedema as a symptom of anaphylaxis and chronic spontaneous urticaria is likely to be mediated by mast cell/basophil activation. Histamine is the central chemical mediator released by mast cells, inducing hyperpermeability and vasodilatation, and is therefore held responsible for the angioedema seen in allergic responses. Indeed, anti-histamine therapy reduces the occurrence of angioedema in urticaria patients [2]. It should be noted that plasma bradykinin levels were not found elevated in four patients with an acute attack of anti-histamine-sensitive angioedema [103]. Yet, evidence accumulates that angioedema in allergic reactions is also accompanied by bradykinin release. FXIIa-C1-INH complexes and kallikrein-C1-INH complexes were increased up to tenfold, within minutes after experimental insect stings in six allergic patients who developed shock or angioedema [1]. In contrast, patients who only developed urticarial rash in reaction to the venom showed a non-significant increase in C1-INH complexes. In line with these results, it was shown that in the patients with angioedema or shock, a third up to half of the total pool of plasma HK was cleaved within minutes [1]. These results were confirmed in another study where HK was analysed in patients with an anaphylactic reaction (mainly induced by food allergens) [104]. In this study, even patients with a mild reaction (i.e. gastro-intestinal complaints) showed $60 \%$ cleavage of their HK pool. Evidence of the clinical relevance of bradykinin during anaphylaxis with hypotension was further demonstrated in animal models. Hypotension after IgE-mediated, antigen-induced anaphylaxis was reduced in FXII-deficient 
mice compared to wild-type mice [104]. The same protection toward IgE-mediated hypotension was reported in BKB2R knockout mice and HK- and PPK-deficient mice [105]. Although direct release of bradykinin from HK by tryptase could also contribute to these findings, it would be reasonable to propose that bradykinin production during anaphylaxis is for a major part FXII-driven.

Moreover, mast cell degranulation may trigger FXII activation via the release of heparin, which activates FXII in vitro and induces FXII-dependent hypotension in mice models [10]. Heparin-induced vascular leakage in mice was diminished by BKB2R antagonist (icatibant) and exaggerated in C1-INH-deficient mice [10]. Heparin is a negatively charged compound, capable of inducing FXII auto-activation. However, like the NETs of neutrophils, heparin binds a large variety of proteins [106]. Contrary to this, a study of $14 \mathrm{HAE}$ patients showed that tryptase levels do not increase during HAE attacks [107]. It might be helpful to keep in mind that in HAE patients that also suffer from allergies, attacks may be aggravated by an allergic trigger. What do these studies mean for HAE? Angioedema attacks in HAE are currently not believed to be mast celldriven ("allergic"), and anti-histamine therapy has no effect on symptoms. So far, there is no solid evidence for an association between allergic responses and angioedema attacks. Additionally, heparin-protein interactions are usually studied in an isolated in vitro manner. However, the possibility of protein-protein interactions on heparin extracellular matrix may be of importance. In the case of FXII, both the net charge of heparin and nearby proteins might synergistically activate FXII. Further research into mast cell and FXII interactions may help to understand the pathological mechanisms behind in vivo FXII activation and angioedema.

The contribution of bradykinin to angioedema with normal levels of C1-INH (i.e. chronic spontaneous urticaria with angioedema, IH-AAE, InH-AAE, U-HAE, etc.) is still uncertain. It might be speculated that since FXII activation can result from mast cell degranulation, bradykinin may also play a supportive role in forms of angioedema that are currently classified as 'histaminergic', based on the presence of wheals, pruritus or (partial) response to anti-histamine therapy. Current studies were unable so far to demonstrate bradykinin or an increased HK cleaving in such patients [103, 104, 108]. Considering the strong evidence of interaction between mast cells and bradykinin production, patients with idiopathic angioedema and recurrent swellings who fail to respond to high-dose anti-histamine treatment might benefit from therapy targeting the contact activation.

\section{Conclusions}

- FXII is an important player in bradykinin production during HAE attacks. However, it is currently unknown how FXII activation occurs in vivo.
- Coagulation parameters change during attacks. This is possibly secondary to vascular leakage, rather than a consequence of FXII activation. However, biomarkers of coagulation may reflect disease activity.

- Fibrinolytic parameters change during attacks. These may reflect a role for plasminogen activation in bradykinin production (via plasmin).

- Multiple lines of evidence demonstrate that contact system activation and bradykinin productioncan be triggered by a variety of cell types, including endothelial cells and mast cells.

- It is possible that bradykinin plays a role in other forms of angioedema with normal Cl-INH activity, including those that are currently classified as histaminergic.

Acknowledgments The work of ZH is supported by a research grant from the UMC Utrecht (Alexandre Suerman grant). We gratefully acknowledge financial support (to $\mathrm{CM}$ ) of the International Patient Organization for $\mathrm{C} 1$ Inhibitor Deficiencies (HAEi) and Stichting Vrienden van Het UMC Utrecht.

Open Access This article is distributed under the terms of the Creative Commons Attribution 4.0 International License (http:// creativecommons.org/licenses/by/4.0/), which permits unrestricted use, distribution, and reproduction in any medium, provided you give appropriate credit to the original author(s) and the source, provide a link to the Creative Commons license, and indicate if changes were made.

\section{References}

1. van der Linden PW, Hack CE, Eerenberg AJ, Struyvenberg A, van der Zwan JK (1993) Activation of the contact system in insectsting anaphylaxis: association with the development of angioedema and shock. Blood 82:1732-1739

2. Zuberbier T, Aberer W, Asero R, Bindslev-Jensen C, Brzoza Z, Canonica GW et al (2014) The EAACI/GA(2) LEN/EDF/WAO Guideline for the definition, classification, diagnosis, and management of urticaria: the 2013 revision and update. Allergy 69:868887

3. Cicardi M, Aberer W, Banerji A, Bas M, Bernstein JA, Bork K et al (2014) Classification, diagnosis, and approach to treatment for angioedema: consensus report from the Hereditary Angioedema International Working Group. Allergy 69:602-616

4. Mansi M, Zanichelli A, Coerezza A, Suffritti C, Wu MA, Vacchini $R$ et al (2015) Presentation, diagnosis and treatment of angioedema without wheals: a retrospective analysis of a cohort of 1058 patients. J Intern Med 277:585-593

5. Zingale LC, Beltrami L, Zanichelli A, Maggioni L, Pappalardo E, Cicardi B et al (2006) Angioedema without urticaria: a large clinical survey. Can Med Assoc J 175:1065-1070

6. Fields T, Ghebrehiwet B, Kaplan AP (1983) Kinin formation in hereditary angioedema plasma: evidence against kinin derivation from $\mathrm{C} 2$ and in support of "spontaneous" formation of bradykinin. J Allergy Clin Immunol 72:54-60

7. Nussberger J, Cugno M, Amstutz C, Cicardi M, Pellacani A, Agostoni A (1998) Plasma bradykinin in angio-oedema. Lancet 351:1693-1697

8. Nussberger J, Cugno M, Cicardi M, Agostoni A (1999) Local bradykinin generation in hereditary angioedema. J Allergy Clin Immunol 104:1321-1322 
9. Müller F, Mutch NJ, Schenk WA, Smith SA, Esterl L, Spronk HM et al (2009) Platelet polyphosphates are proinflammatory and procoagulant mediators in vivo. Cell 139:1143-1156

10. Oschatz C, Maas C, Lecher B, Jansen T, Björkqvist J, Tradler T et al (2011) Mast cells increase vascular permeability by heparininitiated bradykinin formation in vivo. Immunity 34:258-268

11. Maas C, Govers-Riemslag JWP, Bouma B, Schiks B, Hazenberg BPC, Lokhorst HM et al (2008) Misfolded proteins activate factor XII in humans, leading to kallikrein formation without initiating coagulation. J Clin Invest 118:3208-3218

12. White-Adams TC, Berny MA, Patel IA, Tucker EI, Gailani D, Gruber A et al (2010) Laminin promotes coagulation and thrombus formation in a factor XII-dependent manner. J Thromb Haemost 8:1295-1301

13. van der Meijden PEJ, Munnix ICA, Auger JM, Govers-Riemslag JWP, Cosemans JMEM, Kuijpers MJE et al (2009) Dual role of collagen in factor XII-dependent thrombus formation. Blood 114: 881-890

14. Kaplan AP (2010) Enzymatic pathways in the pathogenesis of hereditary angioedema: the role of $\mathrm{C} 1$ inhibitor therapy. J Allergy Clin Immunol 126:918-925

15. Gösswein T, Kocot A, Emmert G, Kreuz W, Martinez-Saguer I, Aygören-Pürsün E et al (2008) Mutational spectrum of the C1INH (SERPING1) gene in patients with hereditary angioedema. Cytogenet Genome Res 121:181-188

16. Dewald G, Bork K (2006) Missense mutations in the coagulation factor XII (Hageman factor) gene in hereditary angioedema with normal C1 inhibitor. Biochem Biophys Res Commun 343:12861289

17. Cichon S, Martin L, Hennies HC, Müller F, Van Driessche K, Karpushova A et al (2006) Increased activity of coagulation factor XII (Hageman factor) causes hereditary angioedema type III. Am J Hum Genet 79:1098-1104

18. Bork K, Wulff K, Meinke P, Wagner N, Hardt J, Witzke G (2011) A novel mutation in the coagulation factor 12 gene in subjects with hereditary angioedema and normal $\mathrm{C} 1$-inhibitor. Clin Immunol 141:31-35

19. Grumach AS, Stieber C, Veronez CL, Cagini N, Constantino-Silva RN, Cordeiro E et al (2016) Homozygosity for a factor XII mutation in one female and one male patient with hereditary angiooedema. Allergy 71:119-123

20. Gelincik A, Demir S, Olgaç M, Karaman V, Toksoy G, Çolakoğlu $\mathrm{B}$ et al (2015) Idiopathic angioedema with F12 mutation: is it a new entity? Ann Allergy Asthma Immunol 114:154-156

21. Longhurst H, Cicardi M (2012) Hereditary angio-oedema. Lancet 379:474-481

22. Hofman ZLM, Relan A, Hack CE (2014) Hereditary angioedema attacks: local swelling at multiple sites. Clin Rev Allergy Immunol 50:34-40

23. Bygum A, Andersen KE, Mikkelsen CS (2009) Selfadministration of intravenous C1-inhibitor therapy for hereditary angioedema and associated quality of life benefits. Eur J Dermatol 19:147-151

24. Cicardi M, Levy RJ, McNeil DL, Li HH, Sheffer AL, Campion M et al (2010) Ecallantide for the treatment of acute attacks in hereditary angioedema. N Engl J Med 363:523-531

25. Cicardi M, Banerji A, Bracho F, Malbrán A, Rosenkranz B, Riedl $M$ et al (2010) Icatibant, a new bradykinin-receptor antagonist, in hereditary angioedema. N Engl J Med 363:532-541

26. Wu MA, Castelli R (2016) The Janus faces of acquired angioedema: C1-inhibitor deficiency, lymphoproliferation and autoimmunity. Clin Chem Lab Med 54:207-214

27. Sinclair D, Smith A, Cranfield T, Lock RJ (2004) Acquired C1 esterase inhibitor deficiency or serendipity? The chance finding of a paraprotein after an apparently low $\mathrm{C} 1$ esterase inhibitor concentration. J Clin Pathol 57:445-447
28. McMurray JJV, Packer M, Desai AS, Gong J, Lefkowitz MP, Rizkala AR et al (2014) Angiotensin-neprilysin inhibition versus enalapril in heart failure. N Engl J Med 371:993-1004

29. Miller DR, Oliveria SA, Berlowitz DR, Fincke BG, Stang P, Lillienfeld DE (2008) Angioedema incidence in US veterans initiating angiotensin-converting enzyme inhibitors. Hypertension 51:1624-1630

30. Kostis JB, Kim HJ, Rusnak J, Casale T, Kaplan A, Corren J et al (2005) Incidence and characteristics of angioedema associated with enalapril. Arch Intern Med 165:1637-1642

31. Maas C (2013) The protease storm of angioedema. J Angioedema 1:18-27

32. Levi M, Hack CE, de Boer JP, Brandjes DP, Büller HR, ten Cate JW (1991) Reduction of contact activation related fibrinolytic activity in factor XII deficient patients. Further evidence for the role of the contact system in fibrinolysis in vivo. J Clin Invest 88: $1155-1160$

33. Braat EA, Dooijewaard G, Rijken DC (1999) Fibrinolytic properties of activated FXII. Eur J Biochem 263:904-911

34. Csuka D, Veszeli N, Imreh É, Zotter Z, Skopál J, Prohászka Z et al (2015) Comprehensive study into the activation of the plasma enzyme systems during attacks of hereditary angioedema due to C1-inhibitor deficiency. Orphanet J Rare Dis 10:132

35. Bork K, Wulff K, Witzke G, Hardt J (2015) Hereditary angioedema with normal C1-INH with versus without specific F12 gene mutations. Allergy 70:1004-1012

36. Joseph K, Tholanikunnel BG, Wolf B, Bork K, Kaplan AP (2015) Deficiency of plasminogen activator inhibitor 2 in plasma of patients with hereditary angioedema with normal $\mathrm{C} 1$ inhibitor levels. J Allergy Clin Immunol. doi:10.1016/j.jaci.2015.07.041

37. Reshef A, Zanichelli A, Longhurst H, Relan A, Hack CE (2015) Elevated D-dimers in attacks of hereditary angioedema are not associated with increased thrombotic risk. Allergy 70:506-513

38. Bork K, Kleist R, Hardt J, Witzke G (2009) Kallikrein-kinin system and fibrinolysis in hereditary angioedema due to factor XII gene mutation Thr309Lys. Blood Coagul Fibrinolysis 20:325-332

39. van Geffen M, Cugno M, Lap P, Loof A, Cicardi M, van Heerde W (2012) Alterations of coagulation and fibrinolysis in patients with angioedema due to C1-inhibitor deficiency. Clin Exp Immunol 167:472-478

40. Relan A, Bakhtiari K, van Amersfoort ES, Meijers JCM, Hack CE (2012) Recombinant C1-inhibitor: effects on coagulation and fibrinolysis in patients with hereditary angioedema. BioDrugs 26 : 43-52

41. Joseph K, Tholanikunnel TE, Kaplan AP (2010) Treatment of episodes of hereditary angioedema with $\mathrm{C} 1$ inhibitor: serial assessment of observed abnormalities of the plasma bradykinin-forming pathway and fibrinolysis. Ann Allergy Asthma Immunol 104:50 54

42. Cugno M, Cicardi M, Bottasso B, Coppola R, Paonessa R, Mannucci PM et al (1997) Activation of the coagulation cascade in C1-inhibitor deficiencies. Blood 89:3213-3218

43. Nielsen EW, Johansen HT, Høgåsen K, Wuillemin W, Hack CE, Mollnes TE (1996) Activation of the complement, coagulation, fibrinolytic and kallikrein-kinin systems during attacks of hereditary angioedema. Scand J Immunol 44:185-192

44. Cugno M, Hack CE, de Boer JP, Eerenberg AJ, Agostoni A, Cicardi M (1993) Generation of plasmin during acute attacks of hereditary angioedema. J Lab Clin Med 121:38-43

45. Donaldson VH (1993) Plasminogen activation in hereditary angioneurotic edema. J Lab Clin Med 121:13-14

46. Cugno M, Bergamaschini L, Uziel L, Cicardi M, Agostoni A, Jie AF et al (1988) Haemostasis contact system and fibrinolysis in hereditary angioedema (C1-inhibitor deficiency). J Clin Chem Clin Biochem 26:423-427 
47. Cullmann W, Kövary PM, Müller N, Dick W (1982) Complement, coagulation and fibrinolytic parameters in hereditary angioedema (HAE). Clin Exp Immunol 49:618-622

48. Mackman N (2009) The role of tissue factor and factor VIIa in hemostasis. Anesth Analg 108:1447-1452

49. Fleck RA, Rao LV, Rapaport SI, Varki N (1990) Localization of human tissue factor antigen by immunostaining with monospecific, polyclonal anti-human tissue factor antibody. Thromb Res 59: 421-437

50. Vadivel K, Bajaj SP (2012) Structural biology of factor VIIa/tissue factor initiated coagulation. Front Biosci (Landmark Ed) 17:24762494

51. Maas C, Meijers JCM, Marquart JA, Bakhtiari K, Weeterings C, de Groot PG et al (2010) Activated factor V is a cofactor for the activation of factor XI by thrombin in plasma. Proc Natl Acad Sci U S A 107:9083-9087

52. Carmeliet P, Mackman N, Moons L, Luther T, Gressens P, Van Vlaenderen I et al (1996) Role of tissue factor in embryonic blood vessel development. Nature 383:73-75

53. Ratnoff OD, Colopy JE (1955) A Familial hemorrhagic trait associated with a deficiency of a clot-promoting fraction of plasma. $\mathrm{J}$ Clin Investig 34:602-613

54. Giangrande PLF (2003) Six characters in search of an author: the history of the nomenclature of coagulation factors. Br J Haematol $121: 703-712$

55. de Maat S, van Dooremalen S, de Groot PG, Maas C (2013) A nanobody-based method for tracking factor XII activation in plasma. Thromb Haemost 109:458-68

56. Iwaki T, Castellino FJ (2006) Plasma levels of bradykinin are suppressed in factor XII-deficient mice. Thromb Haemost 95: $1003-1010$

57. Joseph K, Tholanikunnel BG, Bygum A, Ghebrehiwet B, Kaplan AP (2013) Factor XII-independent activation of the bradykininforming cascade: Implications for the pathogenesis of hereditary angioedema types I and II. J Allergy Clin Immunol 132:470-475

58. Dobó J, Major B, Kékesi KA, Szabó I, Megyeri M, Hajela K et al (2011) Cleavage of kininogen and subsequent bradykinin release by the complement component: mannose-binding lectin-associated serine protease (MASP)-1. PLoS One 6:e20036

59. Kiss N, Barabás E, Várnai K, Halász A, Varga LÁ, Prohászka Z et al (2013) Novel duplication in the F12 gene in a patient with recurrent angioedema. Clin Immunol 149:142-145

60. Olson JD (2015) D-dimer: an overview of hemostasis and fibrinolysis, assays, and clinical applications. Adv Clin Chem 69:1-46

61. Cesarman-Maus G, Hajjar KA (2005) Molecular mechanisms of fibrinolysis. Br J Haematol 129:307-321

62. Declerck PJ, Gils A (2013) Three decades of research on plasminogen activator inhibitor-1: a multifaceted serpin. Semin Thromb Hemost 39:356-364

63. Ellis V, Behrendt N, Danø K (1991) Plasminogen activation by receptor-bound urokinase. A kinetic study with both cellassociated and isolated receptor. J Biol Chem 266:12752-12758

64. Goldsmith GH, Saito H, Ratnoff OS (1978) The activation of plasminogen by Hageman factor (Factor XII) and Hageman factor fragments. J Clin Invest 62:54-60

65. Lenich C, Pannell R, Gurewich V (1995) Assembly and activation of the intrinsic fibrinolytic pathway on the surface of human endothelial cells in culture. Thromb Haemost 74:698-703

66. Pedersen OD, Munkvad S, Gram J, Kluft C, Jespersen J (1993) Depression of factor XII-dependent fibrinolytic activity in survivors of acute myocardial infarction at risk of reinfarction. Eur Heart J 14:785-789

67. Govers-Riemslag JWP, Smid M, Cooper JA, Bauer KA, Rosenberg RD, Hack CE et al (2007) The plasma kallikreinkinin system and risk of cardiovascular disease in men. $\mathrm{J}$ Thromb Haemost 5:1896-1903
68. Tanaka A, Suzuki Y, Sugihara K, Kanayama N, Urano T (2009) Inactivation of plasminogen activator inhibitor type 1 by activated factor XII plays a role in the enhancement of fibrinolysis by contact factors in-vitro. Life Sci 85:220-225

69. Ewald GA, Eisenberg PR (1995) Plasmin-mediated activation of contact system in response to pharmacological thrombolysis. Circulation 91:28-36

70. Pönitz V, Pritchard D, Grundt H, Nilsen DWT (2006) Specific types of activated Factor XII increase following thrombolytic therapy with tenecteplase. J Thromb Thrombolysis 22:199-203

71. Bozkurt S, Arslan ED, Köse A, Ayrık C, Yılmaz A, Dündar GA (2015) Lingual angioedema after alteplase treatment in a patient with acute ischemic stroke. World J Emerg Med 6:74-76

72. Madden B, Chebl RB (2015) Hemi orolingual angioedema after tPA administration for acute ischemic stroke. West J Emerg Med $16: 175-177$

73. Correia AS, Matias G, Calado S, Lourenço A, Viana-Baptista M (2015) Orolingual angiodema associated with alteplase treatment of acute stroke: a reappraisal. J Stroke Cerebrovasc Dis 24:31-40

74. Wallon D, Girardie P, Bombois S, Lucas C (2010) Angioneurotic orolingual oedema following thrombolysis in acute ischaemic stroke. BMJ Case Rep. doi:10.1136/bcr.06.2010.3094

75. Sonny A, Avitsian R, Hussain MS, Elsharkawy H (2015) Angioedema in the neurointerventional suite. J Clin Anesth 27: 170-174

76. Scialò C, Strada L, Finocchi C, Gandolfo C, Balestrino M (2015) Angioedema after rt-PA treatment in acute ischemic stroke may be attended by shock and worsening of stroke outcome. Neurol Sci 36:795-796

77. Wu TY, Wei DY, Baker Y, Sharkey B, Frith RW (2014) Asymmetric oro-facial angioedema following alteplase for acute ischaemic stroke. J Clin Neurosci 21:2004-2006

78. Lin SY, Tang S-C, Tsai L-K, Yeh S-J, Hsiao Y-J, Chen Y-W et al (2014) Orolingual angioedema after alteplase therapy of acute ischaemic stroke: incidence and risk of prior angiotensinconverting enzyme inhibitor use. EurJ Neurol 21:1285-1291

79. Lekoubou A, Philippeau F, Derex L, Olaru A, Gouttard M, Vieillart A et al (2014) Audit report and systematic review of orolingual angioedema in post-acute stroke thrombolysis. Neurol Res 36:687-694

80. Yayan J (2013) Onset of orolingual angioedema after treatment of acute brain ischemia with alteplase depends on the site of brain ischemia: a meta-analysis. N Am J Med Sci 5: 589-593

81. Foster-Goldman A, McCarthy D (2013) Angioedema from recombinant TPA administration: case report and pathophysiology review. Am J Ther 20:691-693

82. Yayan J (2012) Lingual angioedema with macroglossia during the treatment of acute ischemic stroke with alteplase. Int J Gen Med 5: $183-186$

83. Hurford R, Rezvani S, Kreimei M, Herbert A, Vail A, Parry-Jones $A R$ et al (2015) Incidence, predictors and clinical characteristics of orolingual angio-oedema complicating thrombolysis with tissue plasminogen activator for ischaemic stroke. J Neurol Neurosurg Psychiatry 86:520-523

84. de Oliveira DC, Coelho OR, Paraschin K, Ferraroni NR, Zolner R de L (2005) Angioedema related to the use of streptokinase. Arq Bras Cardiol 85:131-134

85. Cooper JP, Quarry DP, Beale DJ, Chappell AG (1994) Life-threatening, localized angio-oedema associated with streptokinase. Postgrad Med J 70:592-593

86. Pechlaner C, Knapp E, Wiedermann CJ (2001) Hypersensitivity reactions associated with recombinant tissue-type plasminogen activator and urokinase. Blood Coagul Fibrinolysis An Int J Haemost Thromb 12:491-494 
87. de Maat $\mathrm{S}$ et al (2016) Plasmin is a natural trigger for bradykinin production in patients with hereditary angioedema with factor XII mutations. J Allergy Clin Immunol. doi:10.1016/j.jaci.2016.02. 021

88. Frank MM, Sergent JS, Kane MA, Alling DW (1972) Epsilon aminocaproic acid therapy of hereditary angioneurotic edema. A double-blind study. N Engl J Med 286:808-812

89. Blohmé G (1972) Treatment of hereditary angioneurotic oedema with tranexamic acid. A random double-blind cross-over study. Acta Med Scand 192:293-298

90. Tengborn L, Blombäck M, Berntorp E (2015) Tranexamic acid-an old drug still going strong and making a revival. Thromb Res 135: 231-242

91. Murphey LJ, Hachey DL, Oates JA, Morrow JD, Brown NJ (2000) Metabolism of bradykinin In vivo in humans: identification of BK1-5 as a stable plasma peptide metabolite. J Pharmacol Exp Ther 294:263-269

92. Suffritti C, Zanichelli A, Maggioni L, Bonanni E, Cugno M, Cicardi M (2014) High-molecular-weight kininogen cleavage correlates with disease states in the bradykinin mediated angioedema due to hereditary c1-inhibitor deficiency. Clin Exp Allergy 44: $1503-1514$

93. Cugno M, Zanichelli A, Bellatorre AG, Griffini S, Cicardi M (2009) Plasma biomarkers of acute attacks in patients with angioedema due to C1-inhibitor deficiency. Allergy 64:254-257

94. Nilsson T, Bäck O (1985) Elevated plasmin-alpha 2-antiplasmin complex levels in hereditary angioedema: evidence for the in vivo efficiency of the intrinsic fibrinolytic system. Thromb Res 40: 817-821

95. Bork K, Witzke G, Artmann K, Benes P, Böckers M, Kreuz W (1984) Interaction between C1-INA, coagulation, fibrinolysis and kinin system in hereditary angioneurotic edema (HANE) and urticaria. Arch Dermatol Res 276:375-380

96. Veszeli N, Csuka D, Zotter Z, Imreh É, Józsi M, Benedek S et al (2015) Neutrophil activation during attacks in patients with hereditary angioedema due to C1-inhibitor deficiency. Orphanet J Rare Dis 10:156

97. Nauseef WM, Borregaard N (2014) Neutrophils at work. Nat Immunol 15:602-611
98. Brower MS, Harpel PC (1982) Proteolytic cleavage and inactivation of alpha 2-plasmin inhibitor and $\mathrm{C} 1$ inactivator by human polymorphonuclear leukocyte elastase. J Biol Chem 257:98499854

99. Stuardo M, Gonzalez CB, Nualart F, Boric M, Corthorn J, Bhoola KD et al (2004) Stimulated human neutrophils form biologically active kinin peptides from high and low molecular weight kininogens. J Leukoc Biol 75:631-640

100. Araújo RC, Kettritz R, Fichtner I, Paiva AC, Pesquero JB, Bader M (2001) Altered neutrophil homeostasis in kinin B1 receptordeficient mice. Biol Chem 382:91-95

101. Wachtfogel YT, Pixley RA, Kucich U, Abrams W, Weinbaum G, Schapira M et al (1986) Purified plasma factor XIIa aggregates human neutrophils and causes degranulation. Blood 67:17311737

102. Oehmcke S, Mörgelin M, Herwald H (2009) Activation of the human contact system on neutrophil extracellular traps. J Innate Immun 1:225-230

103. Nussberger J, Cugno M, Cicardi M (2002) Bradykinin-mediated angioedema. N Engl J Med 347:621-622

104. Sala-Cunill A, Björkqvist J, Senter R, Guilarte M, Cardona V, Labrador M et al (2014) Plasma contact system activation drives anaphylaxis in severe mast cell-mediated allergic reactions. J Allergy Clin Immunol 135:1031-43

105. Proud D, Siekierski ES, Bailey GS (1988) Identification of human lung mast cell kininogenase as tryptase and relevance of tryptase kininogenase activity. Biochem Pharmacol 37:1473-1480

106. Meneghetti MCZ, Hughes AJ, Rudd TR, Nader HB, Powell AK, Yates EA et al (2015) Heparan sulfate and heparin interactions with proteins. J R Soc Interface 12:0589

107. Obtułowicz A, Pirowska M, Dyga W, Czarnobilska E, WojasPelc A (2015) Tryptase and histamine in patients with angioedema due to C1-inhibitor deficiency (Hereditary Angioedema, HAE) and in patients with mastocytosis. Alerg Astma Immunol 20:106-110

108. Lang DM, Sugimoto SL, Curd JG, Christiansen SC, Zuraw BL (1989) High-molecular weight kininogen is cleaved in active erythema multiforme. J Allergy Clin Immunol 83:802-810 